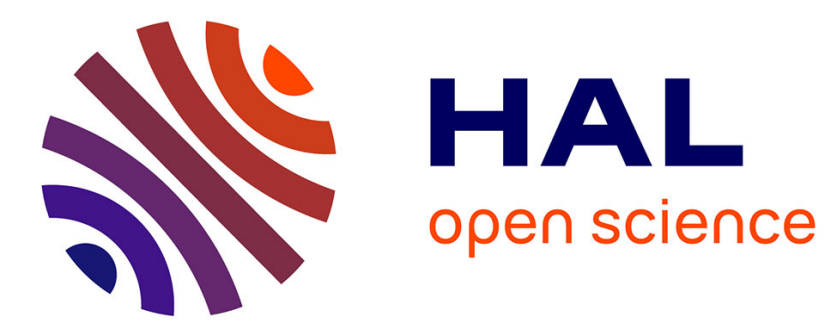

\title{
On Modal Logics of Group Belief
}

Benoit Gaudou, Andreas Herzig, Dominique Longin, Emiliano Lorini

\section{To cite this version:}

Benoit Gaudou, Andreas Herzig, Dominique Longin, Emiliano Lorini. On Modal Logics of Group Belief. Herzig; Andreas and Lorini; Emiliano. The Cognitive Foundations of Group Attitudes and Social Interaction, 5, Springer, pp.75-106, 2015, Studies in the Philosophy of Sociality. hal-03209308

\section{HAL Id: hal-03209308 https://hal.science/hal-03209308}

Submitted on 29 Apr 2021

HAL is a multi-disciplinary open access archive for the deposit and dissemination of scientific research documents, whether they are published or not. The documents may come from teaching and research institutions in France or abroad, or from public or private research centers.
L'archive ouverte pluridisciplinaire HAL, est destinée au dépôt et à la diffusion de documents scientifiques de niveau recherche, publiés ou non, émanant des établissements d'enseignement et de recherche français ou étrangers, des laboratoires publics ou privés. 


\title{
On Modal Logics of Group Belief
}

\author{
Benoit Gaudou, Andreas Herzig, Dominique Longin, and Emiliano Lorini
}

\begin{abstract}
We overview the existing philosophical accounts of group belief, including both aggregative (or reductionist) approaches reducing collective belief to individual beliefs and non-reductionist approaches ascribing beliefs to the group as a whole. We then provide a modal logic of group belief $\mathcal{G L}$ that follows a non-reductionist approach. We compare our group belief logic with the well-known logic of common belief (which is a logic of collective belief in an aggregative sense) and with the logic of group acceptance that has been recently proposed by some of us. Finally, in the spirit of dynamic epistemic logics we propose an extension of $\mathcal{G} \mathcal{L}$ by public announcements.
\end{abstract}

Keywords Group belief • Common belief • Modal logic • Epistemic logic

\section{Introduction}

Individual belief has been studied in depth by philosophers and logicians. The latter have developed formal logics, commonly called epistemic logics or doxastic logics, where belief is interpreted as truth in all worlds that the agent considers possible (Hintikka 1962). However, natural language allows not only to ascribe beliefs to individuals, but also to groups. Consider the following examples.

Example 1 (Tuomela 1992). The team believes that it will win today's game.

Example 2 (Gilbert 2002, p. 35). The United States believe that those responsible for these dreadful acts must be punished.

B. Gaudou $(\varangle) \cdot$ D. Longin

Institut de recherche en informatique de Toulouse (IRIT), University of Toulouse,

Toulouse, France

e-mail: gaudou@irit.fr

A. Herzig • E. Lorini

University of Toulouse, CNRS-IRIT Universite Paul Sabatier, Toulouse Cedex 9, France 
Example 3 (Meijers 2002, p. 70). The British believe that the Euro will eventually be introduced in the UK.

Beyond such toy examples, group belief is actually a central concept in multi-agent systems. For example, the reputation value of a seller in an electronic marketplace can be viewed as a belief of a group of agents about that seller (Herzig et al. 2010).

The attribution to a group of an attitude that was previously only studied at the level of individuals is not so obvious and has to be justified. The concept of Intentionality is useful to clarify this point. For Searle, following Brentano (1995) and Husserl, "Intentionality is that property of many mental states and events by which they are directed at or about or of objects and states of affairs in the world" (Searle 1983, p. 1). This characterization can be applied to many mental states such as belief and intention ${ }^{1}$ : we believe that the earth is flat, we have the intention to go to the dentist. Thus, belief is an Intentional concept and as such, it is intrinsically ascribed to individuals having a mind and therefore mental representations. From this perspective, a collective or a group not having a mind, it appears fallacious and at best metaphorical to ascribe a belief to a group.

Against this immediate and intuitive idea of individualism, Searle among other authors defends the idea of a genuine collective Intentionality: "the capacity for collective behavior is biologically innate, and the forms of collective Intentionality cannot be eliminated or reduced to something else" (Searle 1995, p. 37). But Searle does not go as far as to defend the idea of a collective mind: the notion of collective Intentionality can be defended without being "committed to the idea that there exists some Hegelian world spirit, a collective consciousness, or something equally implausible" (Searle 1995, p. 25). Tollefsen (2002) gives arguments for collective Intentionality: she points out that groups, organizations, institutions, etc. may be viewed as Intentional agents in the same sense as individual agents. She uses an interpretationist approach based on Dennett's notion of Intentional stance (Dennett 1987) to defend her point of view: if attitudes like beliefs, intentions, desires, etc. can be ascribed to an agent then this agent is interpretable as an Intentional agent.

In this paper we take for granted the existence of collective Intentionality, and design a modal logic accounting for the ascription of the particular Intentional state of belief to a group. While there are several philosophical accounts of group belief (that we overview in Sect.2), logical formalizations are much rarer. Two kinds of collective beliefs have been extensively studied in philosophy, artificial intelligence and theoretical computer science: shared belief and common belief (Lewis 1969; Fagin et al. 1995). They are defined in Sect. 2. As we shall see, none of them accounts for the concept of what we are going to call group belief. ${ }^{2}$ One

\footnotetext{
${ }^{1} \mathrm{An}$ intention is just a particular attitude having Intentionality. These two notions should not be mixed up and, following Searle, we write Intentionality with a capital 'I' and intention with a small 'i'.

${ }^{2}$ There is also a third kind of collective belief that was studied in artificial intelligence, distributed belief (Fagin et al. 1995), which can be viewed as the belief held by an external observer who knows all the beliefs of the group members. For example, if agent $i$ believes that $\varphi \longrightarrow \psi$ and agent $j$ believes that $\psi \longrightarrow \chi$ then it is distributed belief in the group of agents made up of $i$ and $j$ that $\varphi \longrightarrow \chi$. Such a kind of group belief is therefore in particular implied by individual belief:
} 
of the crucial issues is the relation between individual belief and collective belief: is collective belief determined by individual belief, and if so, how? In particular, does collective belief imply individual belief? Another crucial issue is introspection: does a group belief imply that every member (and more generally every subgroup) is aware of that group belief? And does absence of a group belief imply that every member (and more generally every subgroup) is aware of that absence of group belief? This will be discussed in depth in Sect. 2; for the time being we give an example highlighting these two issues.

Example 4. Suppose that agent $i_{1}$ thinks privately that agent $i_{0}$ is smart, but that this idea is not widespread. Suppose $i_{1}$ meets $i_{2}$ who often claims publicly that agent $i_{0}$ is dumb; $i_{1}$ and $i_{2}$ discuss agent $i_{0}$ and (for some social reasons) $i_{1}$ asserts that agent $i_{0}$ is really a moron, and this point of view is of course shared by $i_{2}$ : after that, a collective belief that $i_{0}$ is a moron is held by the group made up of $i_{1}$ and $i_{2}$. Then agent $i_{3}$ arrives. Soon the three agents discuss $i_{0}$. As $i_{3}$ is the boss of $i_{1}$ and $i_{2}$, and as $i_{3}$ claims that $i_{0}$ is smart, $i_{1}$ and $i_{2}$ quickly agree: the group made up of $i_{1}, i_{2}$, and $i_{3}$ holds the collective belief that $i_{0}$ is smart. The scenario can be continued, yielding an alternating series of group beliefs about $i_{0}$ 's smartness.

Our example illustrates that the collective beliefs held by $i_{1}, i_{2}$ and $i_{3}$ as a group contradict the collective beliefs held by $i_{1}$ and $i_{2}$, which in turn contradict the individual beliefs of $i_{1}$ and $i_{2}$. It also illustrates that individuals and subgroups introspect group beliefs: when $i_{1}, i_{2}$ and $i_{3}$ as a group hold the belief that $i_{0}$ is smart then $i_{1}, i_{2}$ and $i_{3}$ are individually aware of that. (This is called positive introspection; in Sect. 2 we shall identify conditions under which group belief also satisfies negative introspection.)

Modal logics for different forms of collective belief exist: there are well-studied logics of shared belief, of common belief and of distributed belief. They however cannot account for our example scenario: first, shared belief of a set of agents that $\varphi$ implies shared belief of every subset that $\varphi$; second, common belief of a set of agents that $\varphi$ implies common belief of every subset that $\varphi$; third, distributed belief is not suitable because it does not satisfy introspection: it might be the case that there is distributed belief that $\varphi$ without any agent believing that there is distributed belief that $\varphi$; our example however requires that a group belief of $i_{1}$ and $i_{2}$ that $i_{0}$ is smart to imply that both $i_{1}$ and $i_{2}$ are aware of that group belief.

The preceding considerations motivate the definition of an appropriate logic of group belief, which we undertake in this paper.

The paper is organized as follows. In Sect. 2 we summarize the debate about the ascription of belief to groups. In Sect. 3 we present our logic of group belief. Section 4 extensively discusses the properties of our logic: we assess its properties with respect to the criteria summarized in Sect. 2, compare it to the logic of common belief and to a logic of the (individual and collective) acceptances of the members of an institution that has been recently developed (Gaudou et al. 2008; Lorini et al. 2009), and sketch an extension with public announcements. Section 5 concludes.

if $i$ believes that $\varphi$ then it is distributed belief in every group of which $i$ is a member that $\varphi$. This fundamentally different from the concepts that we study here. 


\section{Theories of Collective Belief}

Several researchers have tried to reduce collective belief to individual belief. We survey these approaches in Sect.2.1. But such a reductionist approach cannot capture all aspects of collective belief, and some researchers have therefore followed a non-reductionist approach. We present their theories in Sect. 2.2. Finally, Sect. 2.3 summarizes the main features of a group belief notion.

Throughout the paper we use the following terminology.

- A collective is any set of individuals.

- A group is a constituted collective: a collective having some structure, some shared goals, rules, etc. An example of a non-constituted collective is the set of all persons having fair hair. See Sect.2.2.1 for more details on the notion of constituted group.

- An individual belief is a belief held by an individual agent. It is therefore private to this agent: no other agent has direct access to this belief.

- A shared belief is a belief that is individually held by each agent in a set of agents: "everybody privately believes that $\varphi$ ". A shared belief is nothing but a conjunction of individual beliefs of the members of this set of agents.

- A common belief is the case when every iteration of individual belief holds. ${ }^{3}$ So a common belief that $\varphi$ is the case if and only if every agent believes $\varphi$, every agent believes that every agent believes $\varphi$, and so on ad infinitum. In the sequel, the term common knowledge refers to a similar definition with knowledge instead of belief.

- A group belief is a belief that is held by a constituted collective, alias a group. (Tuomela uses the term proper group belief (Tuomela 1992).)

- Collective belief is the most general term, subsuming shared belief, common belief and group belief. The collective might be constituted (i.e., it might be a group) or not.

\subsection{Reductionist Approaches of Collective Belief}

Traditionally, collective belief has been viewed as a label of a particular configuration of individual beliefs. This reductionist view of collective belief is called a "summative approach" by Quinton (1976) and Gilbert (1987) and a "statistical" or "aggregative" approach by Tuomela (1992), and is described as an "opinion poll conception" by Meijers (2002). The key point of all these approaches is that such a collective belief is strongly linked to individual beliefs to which it can be reduced, hence the denomination "reductionist approaches". In the sequel we focus on Gilbert's and Tuomela's.

\footnotetext{
${ }^{3}$ Several authors use the term 'mutual belief' instead of common belief, in particular Tuomela (1992).
} 


\subsubsection{Gilbert's Account}

As a first attempt, Gilbert proposes a simple account that is close to the notion of individual belief and is defined as follows:

Definition 1 (Simple summative account Gilbert 1987). A group $J$ collectively believes that $\varphi$ if and only if most of its members believe that $\varphi$.

This account is well-adapted to capture examples such as.

Example 5 (Tuomela 1992). Europeans believe that face-to-face discussants should keep at least half a meter apart from each other.

Indeed, if it appears as the result of an opinion poll on Europeans that most of them think (or assert that they think that) face-to-face discussants should keep at least half a meter apart from each other, it is commonly said that Europeans think so.

If we write $|J|$ for the cardinality of the set $J$ and $\operatorname{Bel}_{i} \varphi$ for "agent $i$ believes that $\varphi$ ", then a collective belief of the set of agents $J$ that $\varphi$ is written as the conjunction

$$
\bigvee_{J^{\prime} \subseteq J,\left|J^{\prime}\right|>\frac{|J|}{2}} \bigwedge_{i \in J^{\prime}} \mathrm{Bel}_{i} \varphi
$$

where $|J|$ is the cardinality of the set $J$.

Gilbert questions this account by means of the following example.

Example 6 (Durkheim and Mauss 1963, p. 44). The Zuni tribe believes that the north is the region of force and destruction.

Suppose that each Zuni believes that the north is the region of force and destruction, and that nobody is aware that his belief is shared (because the Zunis keep their beliefs secret). In this case Definition 1 applies (it is a particular case where $J^{\prime}=J$ ). Nevertheless, it seems counterintuitive to say that the Zuni tribe believes that the north is the region of force and destruction. Therefore the opinion poll approach is too weak to capture the notion of group belief.

We can extend the above criticism to take into account links between agents of a group. We can try to propose the following slightly more complex definition: "a group believes $\varphi$ iff every agent of the group believes that $\varphi$ and that every other member believes it too but thinks that they are alone to have this information". This characterization goes one step further by taking into account the set of agents, but the fact that there is still an individual and secret part in this definition prevents it from properly characterizing group belief. For example if every fierce Zuni warrior thinks that $\varphi$ and believes that every other member thinks so, but is not aware that others are aware that he believes this sentence, then no tribe member will dare to assert that there is a group belief about $\varphi$.

To go even further, a complex summative account of collective belief has been proposed by Gilbert, based on the notion of common knowledge, which is a notion 
that is formally defined, among other works, in philosophy in Lewis $(1969,1972)$, Schiffer (1972), and Heal (1978), in computer science in Fagin et al. (1995), and in economics in Aumann (1976).

Definition 2 (Complex summative account (Gilbert 1987)). A group $J$ collectively believes that $\varphi$ iff:

(1) most of the members of $J$ believe that $\varphi$, and

(2) it is common knowledge in $J$ that (1).

This approach seems better suited to capture the notion of group belief. In particular, a group $J$ with such a belief is aware of its own belief, that is, if $J$ believes $\varphi$ then it is common knowledge in $J$ that $J$ believes $\varphi$. Indeed, if it is common knowledge in $J$ that $\varphi$ then it is common knowledge in $J$ that it is common knowledge in $J$ that $\varphi$. In this sense, an interesting feature of this notion of group belief is its public nature: if $J$ believes $\varphi$ then it is public in $J$ that $J$ believes $\varphi$.

According to that definition, a collective belief of the set of agents $J$ that $\varphi$ has to be written

$$
\bigvee_{J^{\prime} \subseteq J,\left|J^{\prime}\right|>\frac{|J|}{2}}\left(\bigwedge_{i \in J^{\prime}} \operatorname{Bel}_{i} \varphi \wedge \text { CKnow }_{J} \bigwedge_{i \in J^{\prime}} \operatorname{Bel}_{i} \varphi\right)
$$

where $\operatorname{Bel}_{i} \varphi$ stands for "agent $i$ believes that $\varphi$ " and $C \operatorname{Know}_{J} \varphi$ for "it is common knowledge of the agents in $J$ that $\varphi$ ". If we suppose that knowledge is true then this formula is logically equivalent to $\bigvee_{J^{\prime} \subseteq J,\left|J^{\prime}\right|>\frac{|J|}{2}} C K n o w_{J} \bigwedge_{i \in J^{\prime}} \operatorname{Bel}_{i} \varphi$.

But this definition is not free from criticism either because it is built from individual beliefs. In particular, it does not allow members of the group to hold individual ('private') beliefs independently from the collective belief: the collective belief imposes that at least the majority actually holds a concordant belief. However, independence from individual beliefs is a particularly interesting feature of a proper notion of group belief, as we are going to explain in Sect. 2.2.

\subsubsection{Tuomela's We-Belief Account}

Tuomela (1992) investigates several collective attitudes (that he calls "weattitudes"). In particular he proposes an aggregative account of group belief that he calls shared we-belief. Situations where such a belief holds are understood as situations where the members of the group may utter "We believe that $\varphi$ ". His notion of we-belief can be approximately defined as follows.

Definition 3 (Simple We-belief Account (Tuomela 1992)). A group $J$ collectively believes $\varphi$ as "We believe that $\varphi$ " if and only if every agent $i$ member of $J$ believes

(1) that $\varphi$ and,

(2) that it is commonly believed in $J$ that $\varphi$. 
According to Tuomela, this definition suits cases where the set of agents is an aggregate rather than a social, structured group.

Example 7 (Tuomela 1992). The Finns believe that sauna originated in Finland.

Each Finn individually believes that Finland is the country of origin of sauna and that this fact is commonly believed by the Finns. When Tuomela considers Finns in the aggregative sense, he understands only the set of agents with the common feature to have Finnish citizenship. No hierarchical link between the Finns is taken into account: when we want to consider Finns as a structured group having institutions and hierarchies between agents, we should use the term Finland instead of Finns, as in the sentence: "Finland declares war against United States".

If we write $\operatorname{Bel}_{i} \varphi$ for "agent $i$ believes that $\varphi$ " and $\mathrm{CBel}_{J} \varphi$ for "it is common belief of $J$ that $\varphi$ " then the fact that group $J$ collectively believes that $\varphi$ as "We believe that $\varphi$ " (i.e., that members of $J$ share a we-belief that $\varphi$ ) is formally written as:

$$
\bigwedge_{i \in J} \mathrm{Bel}_{i}\left(\varphi \wedge \mathrm{CBel}_{J} \varphi\right)
$$

We note in passing that if we suppose that the logic of individual belief and common belief is the standard normal modal logic $\mathrm{KD}_{4}{ }_{n}^{C}$ then this formula is logically equivalent to $\mathrm{CBel}_{J} \varphi$.

\subsubsection{On the Insufficiencies of Reductionist Approaches}

Although the above approaches seem to suffice to represent many cases of collective belief, they do not account for all of them. In this section we present the main arguments provided by, among others, Gilbert and Meijers highlighting several insufficiencies.

A first argument against both simple and complex summative accounts (cf. Definitions 1 and 2) can be illustrated by the following example.

Example 8 (Gilbert 1987). It is probably common knowledge in the population of adults who have red hair and are over six feet tall that most of them believe that fire burns.

It seems too strong to ascribe a group belief that fire burns to this set of human beings. Indeed, the population of adults who have red hair and are over six feet tall does not necessarily constitute a group: there are no social relationships between the members of this large population, and there is no common identity.

Second, group belief should have a binding effect on the group members. Consider the following example.

Example 9 (Tuomela 1992). The Government believes that war against Iraq will begin soon. 
Here, every agent qua member of the government has to express and act according to the fact that the government believes that war in Iraq is imminent: each member should defend and argue for this belief if it is challenged by another agent, as if it was her personal and private belief. This should however not imply anything with respect to her private beliefs. Moreover, every agent takes it also for granted that every other government member will act so and thus cannot change her mind at the social level (taken as the mental attitudes that he expresses) without any discussion with other government members: every agent is bound to this group belief, and changing her mind at the social level should be the result of a group consensus.

The previous summative accounts do not have anything to say about that binding nature: indeed, nothing in common belief as defined above has a binding or persistent feature. Moreover as soon as an agent privately changes her mind ${ }^{4}$, for any reason or evidence and independently of other group members, the common belief vanishes.

Thirdly, Meijers (2002) argues that this commitment to group belief is conditioned by its acceptance by other members and their commitment to it. Consider the following example that is inspired by the Prisoner's Dilemma.

Example 10. Two criminals were arrested. Both publicly claim that they are innocent. We can thus ascribe to them a group belief that they are innocent. They are examined separately: they still claim that they are innocent and that their partner is also innocent. But if a policeman informs one of them that the other has defected (and if that prisoner believes the policeman), then the latter will typically consider that their binding commitment is broken and might defect, too.

As our example illustrates, every group member is committed to defend the group belief in front of anyone, but as soon as one member violates this commitment, other members no longer have to defend the group belief since the constituted group does not exist anymore. Just as the above feature, this aspect cannot be understood on the basis of a reductionist account of collective belief.

Fourth, the last and perhaps most important argument against the reductionist approaches Meijers (2002) (and also cited by Gilbert (1987) and Tuomela (1992)) is that group belief should be independent from individual beliefs. Tuomela gives the following example.

Example 11 (Tuomela 1992). The Communist Party of Ruritania believes that capitalist countries will soon perish (but none of its members really believes so).

This example highlights that a group can believe a statement without any member believing it privately. Of course, this is an extreme case (called 'spurious collective

\footnotetext{
${ }^{4}$ In Gilbert's simple account, if only one agent changes her mind then the common belief vanishes. In complex accounts, a change of mind of several agents (at worst most of the agents) is needed. However, it is still the case that some agents privately making up their minds may modify the collective belief, independently of any discussion and consensus.
} 
belief' by Tuomela (1992)). However, a correct account of group belief should leave room for situations such as the above one, and a group belief that $\varphi$ should not systematically imply individual beliefs of the group members that $\varphi$. Conversely, Example 6 shows that although every member of the Zuni tribe believes that the north is the region of force and destruction, we cannot ascribe a group belief to the tribe because its members keep their feelings and beliefs secret. Thus, a conjunction of individual beliefs does not necessarily imply group beliefs either. To sum up, a comprehensive account of group belief should keep these two notions independent, in the sense that any of their Boolean combinations should be consistent.

This desideratum was already expressed by Durkheim (1982), who asserts that any proper group belief must be "external to individual consciousness". Indeed, a group belief is often the result of a negotiation, a deliberation or a persuasion process and thus of a consensus between two or more parties with very different viewpoints. It can even be the result of more or less ethical processes such as propaganda or threat (as in Example 11). Durkheim's criterion allows one to handle cases where collective belief is the result of a discussion and where a compromise between each disputant has been reached, as in the following example.

Example 12 (Meijers 2003). A selection committee can believe that a particular candidate is the best candidate for the job, without any of its members believing this individually. Each of them could have a different candidate as their first choice. However, in their role of members of the committee they believe the selected candidate to be the most appropriate for the job.

In this example, the group belief that a particular candidate is the best choice typically results from a voting procedure. Such group belief generating procedures are studied in the field of social choice theory Taylor (2005). We leave aside these more elaborate group belief formation mechanisms in the present logical analysis of group belief and only adopt a very simple principle in the logic of Sect. 3: unanimity.

\subsection{Non-reductionist Accounts: Towards Group Belief}

The above criticisms were the starting point for a new approach to group belief that was mainly led by Gilbert (1987), who considers group belief as a primitive concept that cannot be reduced to individual attitudes. Such accounts are called non-reductionist in the sequel.

\subsubsection{The Plural Subject Account}

Let us begin by an example.

Example 13 (The poetry group (Gilbert 1987)). A group of people meet regularly at one member's house to discuss poetry. The format followed when they meet, 
which evolved informally over time, is as follows. A poem by a contemporary poet is read out. Each participant feels free to make suggestions about how to interpret and evaluate the poem. Others respond, as they see fit, to the suggestions that are made. An opposing view might be put forward, or data adduced to support or refute a suggestion which has been made.

From this discussion a consensual view of the poem will emerge. It will represent the view of the group or the collective opinion about this poem, i.e., it is the belief of the group about this poem. Although this attitude appears to be a belief, it does not have the same properties as collective belief in the summative sense.

In opposition to the summative approach, Gilbert proposes in Gilbert (1989) the following characterization of what she calls group belief. ${ }^{5}$

\section{Definition 4 (The plural subject account (Gilbert 1989)).}

(1) A group $J$ believes that $\varphi$ if and only if the members of $J$ jointly accept that $\varphi$.

(2) The members of $J$ jointly accept that $\varphi$ if and only if it is common knowledge in $J$ that the members of $J$ individually have intentionally and openly expressed their willingness jointly to accept that $\varphi$ with the other members of $J$.

A first thing to observe is that the concept of individual belief is absent from this definition. There is an important reason for untying group beliefs from individual attitudes (and individual beliefs in particular) and for not reducing the former to the latter. While group belief is public with respect to the members of the group, individual attitudes of agents are private, i.e. inaccessible to other agents. We can only have access to them in an indirect way, by observing agents' behaviors and actions, and by trying to interpret them.

Another important aspect of Gilbert's notion of group belief is that it entails both an identification and a mutual recognition with respect to the same group. That is, a group belief of the agents in group $J$ is based on the fact that the agents in $J$ identify themselves as members of this group, recognize each other as members of this group, and accept certain things to stand as the view of the group. We call this kind of set of agents a constituted group. This aspect is explicitly stated in several parts of Gilbert's book. For instance, just before proposing her 'official' notion of group belief she says (Gilbert 1989, p. 289) "I suggest that what is both logically necessary and logically sufficient for the truth of the ascription of group belief here is, roughly, that all or most members of the group have expressed willingness to let a certain view to stand as the view of the group." Some pages later she provides additional clarification: "There are, evidently, various ways of describing the situation of those who have jointly accepted a view with certain others. We may say they have undertaken to express a certain view when acting within, or as a representative of the group. One might even say that someone has accepted a view qua member of a certain group." (Gilbert 1989, p. 304)

\footnotetext{
${ }^{5}$ We note that Gilbert uses indistinctly the terms "collective belief" and "group belief" (Gilbert 1989).
} 
It is also to be noted that Gilbert's notion of group belief implies a common belief of the group about the existence of this group belief: as joint acceptance requires common knowledge of every agent about her willingness to accept the proposition, we can deduce that every member is aware of the group belief, and even that there is common knowledge of this, which also implies common belief of the existence of the group belief. So common knowledge is only about the group belief itself. In contrast, the above Definition 2 requires common knowledge on individual beliefs that $\varphi$ for the summative collective belief that $\varphi$.

Finally, it is to be noted that in Gilbert's mind, the term acceptance has to be taken in the commonsensical use and not in the philosophical sense, where acceptance is opposed to belief. ${ }^{6}$ Moreover, Tuomela (1992) remarks that his own definition is circular: the word joint acceptance is used in its own definition. In reaction to this and the above remark, Gilbert proposed a slightly different characterization of group belief.

Definition 5 (Gilbert 2002). The members of a population $P$ collectively believe that $\varphi$ if and only if they are jointly committed to believe that $\varphi$ as a body.

Joint commitment is a persistent positive attitude toward a decision taken by a group, similarly to personal commitment to stick to an intention until it is fulfilled (Bratman 1987; Cohen and Levesque 1990). As far as Gilbert is concerned, a joint commitment is formed by the expression by every group member of his readiness to be committed to the view of the group. We note that there is common knowledge in the group of this joint commitment; see Part III of Gilbert (1996) for more details. ${ }^{7}$

Tuomela (1992) generalizes the previous approach by introducing the concept of operative members. These are particular members of a group that can impose their beliefs to other members of the group. We do not present his approach in detail here because his concept of operative member does not seem to be a necessary ingredient of the concept of group belief: in many cases the set of operative members of a group is the whole group, e.g. in the case of inhabitants of a country, or families with children old enough to take part in the decision making process (Tuomela 1992).

\subsubsection{Against Gilbert's Plural Subject Account: Belief vs Acceptance}

Some authors reject that group beliefs in Gilbert's sense are really beliefs, and claim that what Gilbert calls belief is another kind of attitude, namely acceptance. Among those who are named rejectionists by Gilbert (2002), we can cite K. Brad Wray (2001, 2003), Anthonie Meijers (1999, 2002, 2003) and Raimo Tuomela (2000).

\footnotetext{
${ }^{6}$ She has explicitly made a distinction between her notion of group belief and acceptance in the philosophical sense in Gilbert (2002). Nevertheless, some authors think that Gilbert's group belief is acceptance in the philosophical sense (see the next section for more details).

${ }^{7}$ We note that this imposes some hypotheses on communication: the channel is perfect, agents are always aware of every information they got, and there is no misunderstanding.
} 
Most of them neither reject the notion of collective Intentionality nor the idea of ascribing mental attitudes to a group, nor are they opposed to Gilbert's plural subject account (our Definition 4). It is rather the nature of the phenomenon the plural subject account describes that is controversial. Everybody agrees that the group belief resulting from the plural subject account is a collective doxastic state, but while Gilbert argues that it corresponds to a form of belief, K. Brad Wray responds (Wray 2001) that " $(. .$.$) the phenomenon that concerns Gilbert is a species$ of acceptance [rather than belief]". Thus rejectionnists agree with non-reductionist approaches of group belief or more generally of collective Intentionality, but they consider that Gilbert's group belief is not a kind of group belief but rather a kind of group acceptance. It is outside the scope of the present paper to go into the details of this debate, and we refer interested readers to Cohen (1989) and Hakli (2006) or to our overview in Lorini et al. (2009). We will however compare in Sect. 4.3 our logic of group belief with the logic of acceptance that we have proposed in Lorini et al. (2009).

\subsection{Toward a Formal Characterization of Group Belief}

In the next section we will propose a formalization of group belief in terms of a logic having a modal operator of group belief. Before this we are going to sum up the main points of the discussion of the present section: they are going to guide our formalization. The five criteria are mainly extracted from Gilbert's plural subject account of group belief, and we view them as proper features of group belief. They also allow to distinguish genuine group belief from aggregate collective belief (that we are going to identify in the sequel with common belief).

Group belief has a binding force. As emphasized by Gilbert (1989), a group belief held by a set of agents $J$ entails that the agents in $J$ identify and recognize themselves as members of the same group, and accept certain things to stand as the view of the group. This might be called the binding force of group belief: if the agents in $J$ hold a certain group belief then they think of themselves as members of the same group, and they are bound by a common identity. From this perspective, when the agents in $J$ hold a group belief then $J$ should not be simply conceived as a set of agents. This binding force is completely ignored in the summative account that we have discussed in Sect. 2.1. It appears explicitly in our official reading of the modal operator of group belief to be introduced in the next section.

No combination of individual beliefs implies group belief. In our view, this is the major argument against the summative approaches. It is inspired by Durkheim (1982), and is one of the most important contributions of Gilbert's account. This property is typically illustrated by Example 6 about the Zuni tribe: the fact that every member of a set of agents believes that $\varphi$ is true is not a sufficient condition for the group belief that $\varphi$. 
Group belief does not imply individual belief. Conversely, this property says that every member of a set $J$ of agents believing that $\varphi$ is not a necessary condition for the group belief that $\varphi$. Together with the previous property, this property means that there should be no entailment link between the group belief operator and the individual belief operator. Thus, our group belief operator will be able to account for Tuomela's "spurious collective beliefs" (cf. Example 11). This contrasts with common belief (on which are based Gilbert's complex summative account and Tuomela's account), which implies individual, private beliefs.

There is a commitment to group belief. As soon as a group belief has been established, even if some group members disagree with this belief, they must act in compliance with it, i.e., they are committed to this belief. When they violate this commitment they are liable for sanctions, ranging from blames (Gilbert 1987) to exclusion from the group (Tuomela 1992). In the sequel, we will not consider a fine sanction system; instead we logically forbid violation of a group belief by a member of a constituted group, in the sense that if a set of agents publicly holds beliefs that are jointly inconsistent then it cannot constitute a group.

The group members hold a common belief about group beliefs. One of the major criticisms against the "simple summative approach" is that every group member may individually believe that $\varphi$ without any collective belief that $\varphi$ because agents are not aware of the other agents' beliefs. A kind of common belief is thus necessary, but not about the content of the group belief (as in the "complex summative approach"), but rather about the group belief itself: the group belief is public for every member of this group. Tuomela (1992) defends this thesis arguing that group belief is built due to a joint and intentional group action: if such a group action has occurred then this is known by each agent (and is even common knowledge). This entails that every member of the group is aware of all group beliefs.

The above five previous requirements constitute the main features of a group belief operator. They are precious guidelines in our logical formalization of group belief. Nevertheless they will not be translated directly into the logical axioms to be presented in Sect. 3.3: the positive requirements will be derived from the logical principles that we will adopt, and the negative requirements will not be derivable due to some principles that we are going to reject. This will be discussed in Sect. 4.2.1.

\section{A Logic of Group Belief}

We now turn to a logical formalization of Gilbert's non-reductionist group belief. Our logic is based on the standard multi-modal logic of individual belief KD45 (Fagin et al. 1995). We augment this logic by a modal operator of group belief and call the resulting logic the logic of group belief, noted $\mathcal{G} \mathcal{L}$. We first present the Kripke semantics of our logic and then axiomatize its validities. In Sect. 4 we will extend $\mathcal{G L}$ with operators of common belief and of public announcement. 


\subsection{Syntax}

Let $A G T$ be a finite set of agents. We use $i, j, \ldots$ to denote elements of $A G T$, and $J, J^{\prime}, \ldots$ to denote non-empty subsets of $A G T{ }^{8}$ Let $A T M=\{p, q, \ldots\}$ be a countable set of propositional letters. The language of our logic $\mathcal{G L}$ is defined by the following grammar:

$$
\varphi::=p|\neg \varphi| \varphi \vee \varphi \mid \mathrm{GBel}_{J} \varphi
$$

where $p$ ranges over $A T M$ and $J$ over $2^{A G T} \backslash\{\emptyset\}$. When $J$ is a singleton then we write $\operatorname{GBel}_{i} \varphi$ instead of $\operatorname{GBel}_{\{i\}} \varphi$. We identify $\operatorname{GBel}_{i} \varphi$ with the individual belief $\operatorname{Bel}_{i} \varphi$. The Boolean connectives $\wedge, \rightarrow, \leftrightarrow, \top$ and $\perp$ are defined from $\vee$ and $\neg$ in the usual manner.

$\mathrm{GBel}_{J} \varphi$ reads "while the set of agents $J$ is a constituted group then $J$ believes as a whole that $\varphi$ holds". Therefore $G B e l_{J} \perp$ may be read "The set of agents $J$ is not a constituted group" and $\neg \mathrm{GBel}_{J} \perp \wedge \mathrm{GBel}_{J} \varphi$ may be read "the set of agents $J$ is a constituted group and believes $\varphi$ ", or "the group $J$ believes $\varphi$ ". In the case of a singleton $\{i\}$, we identify the group belief operator $\operatorname{GBel}_{\{i\}}$ with the individual belief operator, avoiding thus a particular operator of individual belief. $\mathrm{GBel}_{\{i\}} \varphi$ reads "agent $i$ believes that $\varphi$ holds". We sometimes also say that $i$ individually believes that $\varphi$, or that $i$ privately believes that $\varphi$. For convenience, we write $G_{B e l} \varphi$ for $\operatorname{GBel}_{\{i\}} \varphi$.

\subsection{Semantics}

A model $M$ of the logic of group belief includes a nonempty set of possible worlds $W$ and a valuation function $\mathscr{V}: A T M \longrightarrow 2^{W}$ associating to each propositional letter $p$ the set of worlds where $p$ is true. Models moreover contain accessibility relations that will be detailed in the sequel.

To each possible world $w$ and each non-empty set of agents $J \subseteq A G T$, we associate the set of possible worlds $\mathscr{G}_{J}(w)$ that are consistent with all propositions believed in world $w$ by $J . \mathscr{G}_{J}(w)$ contains those worlds that are consistent with what is believed by $J$. Formally, we have a mapping $\mathscr{G}:\left(2^{A G T} \backslash\{\emptyset\}\right) \longrightarrow$ $2^{W \times W}$ associating an accessibility relation to each non-empty subset of $A G T$. For convenience, we write $\mathscr{G}_{i}$ instead of $\mathscr{G}_{\{i\}}$.

For a given model $M$, the truth condition for $\mathrm{GBel}_{J}$ stipulates that $\varphi$ is believed by $J$ at $w$, noted $M, w \models G B e l_{J} \varphi$, if and only if $\varphi$ holds in every world that $J$ can access from $w$ via $\mathscr{G}_{J}$ :

$$
M, w \models \operatorname{GBel}_{J} \varphi \text { iff } M, w^{\prime} \models \varphi \text { for every } w^{\prime} \in \mathscr{G}_{J}(w) .
$$

\footnotetext{
${ }^{8}$ It does not make too much sense to talk about the belief of an empty set of agents. We refer to Ågotnes (2012) for a thorough investigation of the formal issues related to empty groups.
} 


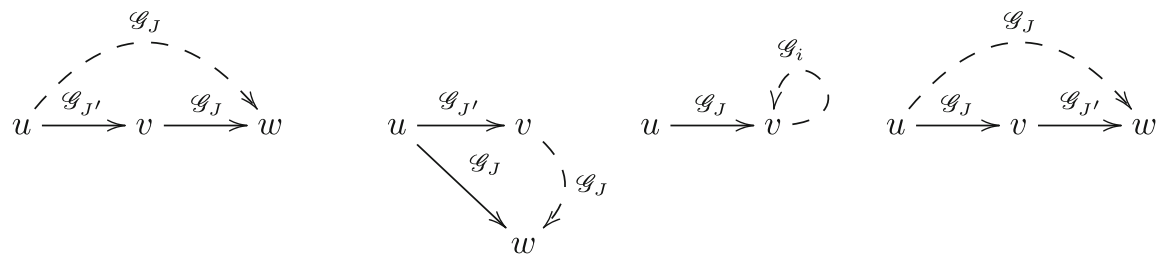

Fig. 1 Schemas for conditions 1, 2, 3 and 4

We impose the following constraints on accessibility relations of $\mathcal{G} \mathcal{L}$ models, for sets of agents $J$ and $J^{\prime}$ such that $J^{\prime} \subseteq J$ and $J^{\prime} \neq \varnothing$ :

1. if $u \mathscr{G}_{J^{\prime}} v$ and $v \mathscr{G}_{J} w$ then $u \mathscr{G}_{J} w$;

2. if $u \mathscr{G}_{J^{\prime}} v$ and $u \mathscr{G}_{J} w$ then $v \mathscr{G}_{J} w$;

3. if $u \mathscr{G}_{J} v$ then there is $i \in J$ such that $v \mathscr{G}_{i} v$;

4. if $u \mathscr{G}_{J} v$ and $v \mathscr{G}_{J^{\prime}} w$ then $u \mathscr{G}_{J} w$.

Constraint 1 stipulates that agents of a subset $J^{\prime}$ of the set $J$ are aware of what is collectively believed by the group $J$ : whenever $w$ is a world for which it is believed by $J^{\prime}$ that all $J$-believed propositions hold in $w$, then all $J$-believed propositions indeed hold in $w$ (Fig. 1). Similarly, 2 expresses that subgroups are aware of what is not believed in the group, too (Fig. 1). Together, these two constraints are a kind of attention property: each subgroup is aware of what is believed (and not believed) by the group. This is justified by Gilbert's hypothesis that the commitment towards a group belief is common knowledge. 1 and 2 can be put together: if $u \mathscr{G}_{J^{\prime}} v$ then $\mathscr{G}_{J}(u)=\mathscr{G}_{J}(v)$, i.e., if $u \mathscr{G}_{J} v$ then what is believed by $J$ at $u$ is the same as what is believed by $J$ at $v$. From 1 and 2 it also follows that $\mathscr{G}_{J}$ is transitive and Euclidian. 3 says that it is believed by a group $J$ that if a proposition is believed by each of $J$ 's members then it is true, too. This is a kind of unanimous adoption of group belief. 4 says that if a formula is believed by a group $J$ then it is believed by $J$ that this information is believed by every subgroup of $J$ (Fig. 1).

The accessibility relations $\mathscr{G}_{J}$ are not necessarily serial: seriality of $\mathscr{G}_{J}$ means that $J$ is a constituted group. However, we assume that individual agents are rational and thus that their beliefs stay consistent. We therefore impose:

5. $\mathscr{G}_{i}$ is serial, for every $i \in A G T$.

In words, at least one world exists that is consistent with the set of individually believed propositions.

Remark 1. Note that our constraints do not guarantee that $\mathscr{G}_{J^{\prime}} \subseteq \mathscr{G}_{J}$, for $J^{\prime} \subseteq$ $J$. They do not guarantee either that when $u \mathscr{G}_{J^{\prime}} v$ and $u \mathscr{G}_{J} w$ then $v \mathscr{G}_{J^{\prime}} w$ : together with 1 , it would imply that $\mathscr{G}_{J^{\prime}}(u) \subseteq \mathscr{G}_{J}(u)$ as soon as $\mathscr{G}_{J}(u) \neq \emptyset$.

\section{Definition 6.}

- $\varphi$ is true in $M(M \models \varphi)$ iff $M, w \models \varphi$ for every $w \in W$.

- $\varphi$ is valid in a class of models $\mathrm{C}$ (noted $\models_{\mathrm{C}} \varphi$ ) iff $M \models \varphi$ for every $M \in \mathrm{C}$.

- $S \models \mathrm{C} \varphi$ iff for every $M \in \mathrm{C}$, if $M \models \psi$ for every $\psi \in S$ then $M \models \varphi$. 
The class of all Kripke models satisfying 1, 2, 3, 4 and 5 is called $\mathcal{G} \mathcal{L}$. We write $\models_{\mathcal{G L}} \varphi$ when a formula $\varphi$ is valid in the class $\mathcal{G} \mathcal{L}$.

\subsection{Axiomatics}

The validities of $\mathcal{G} \mathcal{L}$ are axiomatized as follows:

$$
\begin{aligned}
& \frac{\varphi}{\text { GBel }_{J} \varphi} \\
& \operatorname{GBel}_{J}(\varphi \rightarrow \psi) \rightarrow\left(\text { GBel }_{J} \varphi \rightarrow \text { GBel }_{J} \psi\right) \\
& \text { GBel }_{J} \varphi \rightarrow \text { GBel }_{J^{\prime}} \operatorname{GBel}_{J} \varphi \quad \text { if } J^{\prime} \subseteq J \\
& \neg \mathrm{GBel}_{J} \varphi \rightarrow \mathrm{GBel}_{J^{\prime}} \neg \mathrm{GBel}_{J} \varphi \text { if } J^{\prime} \subseteq J \\
& \operatorname{GBel}_{J}\left(\left(\bigwedge_{i \in J} \operatorname{GBel}_{i} \varphi\right) \rightarrow \varphi\right) \\
& \text { GBel }_{J} \varphi \rightarrow \text { GBel }_{J} \text { GBel }_{J^{\prime}} \varphi \text { if } J^{\prime} \subseteq J \\
& \text { GBel }_{i} \varphi \rightarrow \neg \text { BBel }_{i} \neg \varphi \\
& \left(\mathrm{RN}_{\text {GBel }}\right) \\
& \left(\mathrm{K}_{G B e l_{J}}\right) \\
& (\mathrm{IN}+) \\
& \text { (IN-) }
\end{aligned}
$$

The last five axioms respectively correspond to constraints 1-5.

The axioms of positive and negative introspection ( $\mathrm{IN}+$ ) and ( $\mathrm{IN}-$ ) correspond to constraints 1 and 2 , and express that if a proposition $\varphi$ is believed (resp. not believed) by the set of agents $J$ then it is believed by each subset that $\varphi$ is believed (resp. not believed) by $J$. This is due to the public character of the group belief operator. In particular, each agent $i$ member of $J$ is aware of what is believed (resp. not believed) by the group $J$ : if $i \in J$ then both $\operatorname{GBel}_{J} \varphi \rightarrow \mathrm{GBel}_{i} \mathrm{GBel}_{J} \varphi$ and $\neg \mathrm{GBel}_{J} \varphi \rightarrow \mathrm{GBel}_{i} \neg \mathrm{GBel}_{J} \varphi$ (set $J=\{i\}$ to see this). The schemas (IN+) and (IN-) therefore generalize the positive and negative introspection axioms for individual belief.

The axiom (UNA) corresponds to the semantic constraint 3, and expresses that it is collectively believed by $J$ that if every member of $J$ individually believes $\varphi$ then $\varphi$ is true. It is important to remark here that the formula $\operatorname{GBel}_{J} \mathrm{GBel}_{i} \varphi$ (with $i \in J$ ) has a particular status. We consider that this formula has as primary origin the expression of $i$ 's belief that $\varphi$ holds. Following speech act theory (Searle 1969), the assertion of $\varphi$ by $i$ counts as the public expression of his belief that $\varphi$. We observe that other group members do not have any access to the truth of $\operatorname{GBel}_{i} \varphi$. Therefore this individual belief expressed to the group is automatically believed by the group. (This is a shortcut, because it presupposes a perfect communication channel.) In the case where the acceptance of this fact induces an inconsistency with previous group beliefs we consider that the set of agents is no longer a constituted group. We stress that $i$ 's public expression of his belief that $\varphi$ in front of group $J$ neither implies that $i$ privately believes that $\varphi$, nor that the members of $J$ privately believe that $\varphi$. 
The axiom (AGR) corresponds to the semantic constraint 4, and is an agreement axiom: it says that if $\varphi$ is believed by $J$ then it is believed by $J$ that the formula is believed by each subset $J^{\prime}$ of $J$. Note that this does not imply that $\varphi$ is actually believed by every subset $J^{\prime}$ of $J$, i.e., (AGR) does not entail $\mathrm{GBel}_{J} \varphi \rightarrow \mathrm{GBel}_{J^{\prime}} \varphi$. In particular, the fact that $\varphi$ is believed by $J$ does not imply that the members of $J$ individually believe that $\varphi$, i.e., $\operatorname{GBel}_{J} \varphi \rightarrow \operatorname{GBel}_{i} \varphi$ is invalid (regardless whether $i \in J$ or not). Thanks to this axiom we have the following theorems:

$$
\begin{gathered}
\operatorname{GBel}_{J}\left(\varphi \wedge \mathrm{GBel}_{i} \neg \varphi\right) \rightarrow \text { GBel }_{J} \perp \text { if } i \in J \\
\mathrm{GBel}_{J}\left(\mathrm{GBel}_{i} \varphi \wedge \mathrm{GBel}_{j} \mathrm{GBel}_{i} \neg \varphi\right) \rightarrow \mathrm{GBel}_{J} \perp \text { if } i, j \in J
\end{gathered}
$$

The former theorem highlights a property of Gilbert's notion of group belief (or acceptance) according to which it is implausible that a constituted group $J$ agrees to have a collective view that $\varphi$ and, at the same time, agrees that someone in $J$ has a dissident point of view, i.e., someone in $J$ believes that $\neg \varphi$.

Together, (AGR) and (UNA) entail the following theorem:

$$
\operatorname{GBel}_{J} \varphi \leftrightarrow\left(\mathrm{GBel}_{J} \bigwedge_{i \in J} \mathrm{GBel}_{i} \varphi\right)
$$

Thus it is believed by a group of agents $J$ that $\varphi$ holds if and only if it is believed by $J$ that each of its members believes $\varphi$. This illustrates the process of group belief establishment by consensus that is 'built in' in our logic.

Note that the conjunction $\neg \mathrm{GBel}_{i} \varphi \wedge \mathrm{GBel}_{J} \mathrm{GBel}_{i} \varphi$ is in general consistent in our logic. This means that where group beliefs are formed by principles other than unanimity - such as by majority voting in selection committees-then all group members are supposed to publicly adopt the group belief. They may however privately disagree with the outcome (which may also be due to the fact that they lied when they expressed their individual beliefs). For example, once the view of the set of ministers $J$ of some government has been decided then it becomes a group belief of $J$ that every member who had disagreed changes his mind and adopts the government view. Note also that in the special case where $J$ equals the singleton $\{i\}$, the conjunction $\neg \operatorname{GBel}_{i} \varphi \wedge \mathrm{GBel}_{i} \mathrm{GBel}_{i} \varphi$ is inconsistent due to axiom $\left(\mathrm{D}_{G B e l_{i}}\right)$ for $\mathrm{GBel}_{i}$ (as well as axiom (IN-)).

The axiom $\left(\mathrm{D}_{G B l_{i}}\right)$ corresponds to the constraint 5, and is proper to individual belief. It expresses that individuals are always constituted groups.

Using (IN+), (IN-) and $\left(\mathrm{D}_{\text {GBel }_{i}}\right)$ we can moreover show the following:

$$
\begin{gathered}
\operatorname{GBel}_{J} \varphi \leftrightarrow \mathrm{GBel}_{i} \mathrm{GBel}_{J} \varphi \text { if } i \in J \\
\neg \mathrm{GBel}_{J} \varphi \leftrightarrow \mathrm{GBel}_{i} \neg \mathrm{GBel}_{J} \varphi \text { if } i \in J
\end{gathered}
$$

These theorems express that every agent is aware of what is believed (resp. not believed) by the set of agents he is member of. 
It follows from axioms (IN+) and (IN-) that the modal axioms 4 and 5 (Chellas 1980) are provable in $\mathcal{G} \mathcal{L}$ for every $\mathrm{GBel}_{J}$ operator: these are therefore normal modal operators of type K45. Together with axiom $\left(\mathrm{D}_{G B l_{i}}\right)$ this means that the logic of individual belief is the standard doxastic logic $\mathrm{KD}_{4} 5_{n}$.

\section{Soundness and Completeness of $\mathcal{G} \mathcal{L}$}

A formula $\varphi$ is a theorem of logic $\mathcal{G} \mathcal{L}$ if $\varphi$ is provable from the axioms of classical propositional logic together with $\left(\mathrm{K}_{G_{B e l_{J}}}\right),(\mathrm{IN}+),(\mathrm{IN}-),(\mathrm{UNA}),(\mathrm{AGR})$ and $\left(\mathrm{D}_{G B e l_{i}}\right)$, by means of the inference rules modus of ponens and $\left(\mathrm{RN}_{G B e l_{J}}\right)$. Theoremhood of $\varphi$ in $\mathcal{G L}$ is noted $\vdash_{\mathcal{G L}} \varphi$.

The inference rule $\mathrm{RN}_{G B e l_{J}}$ and the axiom $\mathrm{K}_{G B e l_{J}}$ tell us that our logic is a normal modal logic. Each of the other axioms, i.e., IN+, IN-, UNA, AGR, GBel $_{i}$ have the syntactical form of so-called Sahlqvist axioms (Sahlqvist 1975). Therefore each of them has a corresponding semantical constraint on frames, viz. our constraints 1-5 making up the class of $\mathcal{G} \mathcal{L}$ models. Then by Sahlqvist's general completeness result, our axiomatics constitutes a sound and complete axiomatization of the formulas that are valid in the class of $\mathcal{G} \mathcal{L}$ models.

Theorem 1. For every formula $\varphi, \models_{\mathcal{G L}} \varphi$ if and only if $\vdash_{\mathcal{G L}} \varphi$.

We note that Sahlqvist's theorem also implies that the extension by any combination of IN+, IN-, UNA, AGR, $\mathrm{D}_{G B l_{i}}$ of the basic normal modal logic (axiomatized by $\mathrm{RN}_{G B e l_{J}}, \mathrm{~K}_{\text {GBel }_{J}}$ ) is sound and complete w.r.t. the class of models obeying the corresponding constraints.

\subsection{Some Invalid Formulas}

Here are some properties that we have chosen to reject. In the sequel, $J^{\prime}$ denotes a subset of a set of agents $J$.

Not all sets of agents are groups. Contrarily to individual belief, we do not consider that axiom $\mathrm{D}$ should be valid for group belief:

$$
\nvdash \neg G B e l_{J} \perp
$$

In order for $\neg \mathrm{GBel}_{J} \perp$ to hold $J$ should not simply be a set of agents but rather a constituted group. This is also related to our axiom (AGR): for example the formula GBel $_{J} \varphi \wedge \mathrm{GBel}_{J} \mathrm{GBel}_{i} \neg \varphi$ should be consistent, but should imply that $J$ is not a constituted group. The latter is due to the fact that the members of $J$ (publicly) disagree about what should be a common body of beliefs.

Being a constituted group is not closed under subsets. We have:

$$
\nvdash \neg \mathrm{GBel}_{J} \perp \rightarrow \neg \mathrm{GBel}_{J^{\prime}} \perp
$$


in particular when $J^{\prime} \subset J$. For example, consider the set $J=\{1,2, \ldots, 11\}$ of 11 agents making up a football team: $J$ is a constituted group, but none of its subsets is so. More precisely, every agent in $\{1,2, \ldots, 11\}$ identifies himself as a member of the group and recognizes $J$ as a group. This does not entail that $\{1,2, \ldots, 10\}$ constitute a group. Indeed, it is not the case that every agent in $\{1,2, \ldots, 10\}$ recognizes $\{1,2, \ldots, 10\}$ as a group because we consider that ten players do not constitute a football team.

Group belief does not imply subgroup belief. We have:

$$
\nvdash\left(\neg \mathrm{GBel}_{J} \perp \wedge \mathrm{GBel}_{J} \varphi\right) \rightarrow\left(\neg \mathrm{GBel}_{J^{\prime}} \perp \wedge \mathrm{GBel}_{J^{\prime}} \varphi\right)
$$

in particular when $J^{\prime} \subset J$. We reject this because group belief should not imply individual belief. More generally, a fraction of a big group might disagree with a group belief entertained by the whole group if the group belief was e.g. obtained by a majority vote. For example, in 2007 the US Democrats held the group belief that Obama was the best candidate for presidency while the subset of Clinton supporters disagreed. Non-validity of the implication already follows from non-validity of the preceding implication. We moreover have $\nvdash \operatorname{GBel}_{J} \varphi \rightarrow \operatorname{GBel}_{J^{\prime}} \varphi$.

\subsection{Example}

To illustrate our logic we model the example of Sect. 1.

1. Agent $i_{1}$ (privately) believes that $i_{0}$ is smart: GBel $_{i_{1}}$ smart $_{i_{0}}$.

2. Agents $i_{1}$ and $i_{2}$ discuss and reach the consensus that $i_{0}$ is not smart: $\operatorname{GBel}_{\left\{i_{1}, i_{2}\right\}} \neg \operatorname{smart}_{i_{0}}$. (This follows from $\operatorname{GBel}_{\left\{i_{1}, i_{2}\right\}} \operatorname{GBel}_{i_{1}} \neg \operatorname{smart}_{i_{0}} \wedge \operatorname{GBel}_{\left\{i_{1}, i_{2}\right\}}$ GBel $_{i_{2}} \neg$ smart $_{i_{0}}$.)

3. Agent $i_{3}$ joins the conversation and they attain the consensus that $i_{0}$ is smart: GBel $_{\left\{i_{1}, i_{2}, i_{3}\right\}}$ smart $_{i_{0}}$.

This illustrates that we might have consistent beliefs of nested constituted groups $\left\{i_{1}\right\} \subset\left\{i_{1}, i_{2}\right\} \subset\left\{i_{1}, i_{2}, i_{3}\right\}$ about propositions that change at each level of nesting:

$$
\begin{aligned}
\neg \operatorname{GBel}_{i_{1}} \perp \wedge \operatorname{GBel}_{i_{1}} \text { smart }_{i_{0}} \wedge & \neg \operatorname{GBel}_{\left\{i_{1}, i_{2}\right\}} \perp \wedge \operatorname{GBel}_{\left\{i_{1}, i_{2}\right\}} \neg \operatorname{smart}_{i_{0}} \wedge \\
& \neg \operatorname{GBel}_{\left\{i_{1}, i_{2}, i_{3}\right\}} \perp \wedge \operatorname{GBel}_{\left\{i_{1}, i_{2}, i_{3}\right\}} \operatorname{smart}_{i_{0}}
\end{aligned}
$$

Fig. 2 contains a model of the situation after the interaction between $i_{1}$ and $i_{2}$, that is described by the formula $\varphi=$ GBel $_{i_{1}}$ smart $_{i_{0}} \wedge \neg G B e l_{\left\{i_{1}, i_{2}\right\}} \perp \wedge \operatorname{GBe}_{\left\{i_{1}, i_{2}\right\}} \neg \operatorname{smart}_{i_{0}}$.

\section{Discussion}

We now discuss several properties of our logic of group belief $\mathcal{G L}$. We first compare $\mathcal{G L}$ with the logic of common belief. We then assess $\mathcal{G L}$ with respect to Gilbert's and Tuomela's non-reductionist theories of group belief as expounded in Sect. 2.2. 
Fig. 2 Model after the interaction between agents $i_{1}$ and $i_{2}$ (Formula $\varphi$ holds in the left world)

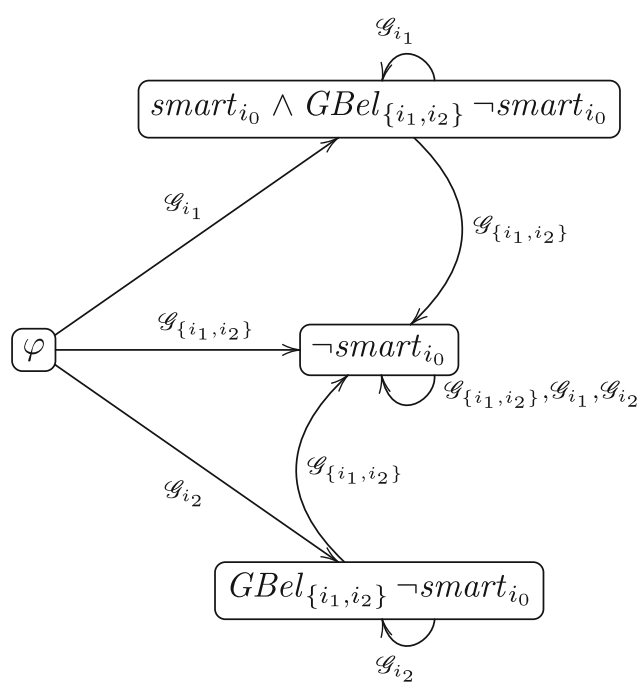

In the third part we compare the logic of group belief and the logic of collective acceptance. We finally sketch a dynamic extension of $\mathcal{G} \mathcal{L}$ where group beliefs can be updated, as in public announcement logic (PAL) (Baltag et al. 1998).

\subsection{Discussion: The Relation Between Group Belief and Common Belief}

Suppose we add a further modal operator $\mathrm{CBel}_{J}$ to the language of $\mathcal{G L}$. The formula $\mathrm{CBel}_{J} \varphi$ reads "the agents in $J$ commonly believe that $\varphi$ holds". Let us first recall semantics and axiomatics of common belief (Fagin et al. 1995).

\subsubsection{Semantics of Common Belief}

Common belief of a group of agents is semantically defined from individual belief: the mapping $\mathscr{C}:\left(2^{A G T} \backslash\{\emptyset\}\right) \longrightarrow\left(W \longrightarrow 2^{W}\right)$ associates an accessibility relation $\mathscr{C}_{J}$ to each group $J \subseteq A G T$ such that

6. $\mathscr{C}_{J}=\left(\bigcup_{i \in J} \mathscr{G}_{i}\right)^{+}$

For each group $J, \mathscr{C}_{J}$ is therefore the transitive closure of the union of the set of accessibility relations associated to $J$ 's members. (Remember that we identify $\mathrm{GBel}_{i}$ with the operator of individual belief.) $\mathscr{C}_{J}(w)$ is the set of possible worlds compatible with common beliefs of the group $J$. 
So common belief is an aggregative kind of collective belief: it can be semantically reduced to individual beliefs (in terms of accessibility relations). ${ }^{9}$

\subsubsection{Axiomatics of Common Belief}

Axiomatically, common belief is defined by the Fixpoint Axiom $\left(\mathrm{FP}_{\mathrm{CBel}_{J}}\right)$ and the Least Fixpoint Axiom $\left(\mathrm{LFP}_{\mathrm{CBel}_{J}}\right)$ :

$$
\begin{array}{cc}
\mathrm{CBel}_{J} \varphi \leftrightarrow \bigwedge_{i \in J} \operatorname{GBel}_{i}\left(\varphi \wedge \mathrm{CBel}_{J} \varphi\right) & \left(\mathrm{FP}_{\mathrm{CBel}_{J}}\right) \\
\left(\bigwedge_{i \in J} \operatorname{GBel}_{i} \varphi \wedge \mathrm{CBel}_{J}\left(\varphi \rightarrow \bigwedge_{i \in J} \mathrm{GBel}_{i} \varphi\right)\right) \rightarrow \operatorname{CBel}_{J} \varphi & \left(\mathrm{LFP}_{\mathrm{CBel}_{J}}\right)
\end{array}
$$

It follows from these axioms that the logic of $\mathrm{CBel}_{J}$ contains KD4; in particular:

$$
\begin{array}{rlrl}
\mathrm{CBel}_{J} \varphi & \rightarrow \neg \mathrm{CBel}_{J} \neg \varphi & \left(\mathrm{D}_{\mathrm{CBel}_{J}}\right) \\
\mathrm{CBel}_{J} \varphi \rightarrow \mathrm{CBel}_{J} \mathrm{CBel}_{J} \varphi & \left(4_{\mathrm{CBel}_{J}}\right)
\end{array}
$$

Note that the negative introspection axiom 5 is not a theorem for $\mathrm{CBel}$ : the formula $\neg \mathrm{CBel}_{J} \varphi \rightarrow \mathrm{CBel}_{J} \neg \mathrm{CBel}_{J} \varphi$ is not valid (Bonanno and Nehring 2000). In particular, from $\left(\mathrm{D}_{\mathrm{CBel}_{J}}\right)$ and $\left(5_{\mathrm{CBel}_{J}}\right)$ we could deduce that $\mathrm{CBel}_{J^{\prime}} \mathrm{CBel}_{J} \varphi \rightarrow$ $\mathrm{CBel}_{J} \varphi$ holds, which would mean that a group member cannot be wrong about a common belief of the group.

It follows from the Fixpoint Axiom that common belief implies individual belief:

$$
\operatorname{CBel}_{J} \varphi \rightarrow \bigwedge_{i \in J} \operatorname{GBel}_{i} \varphi
$$

\subsubsection{Common Belief vs Group Belief}

Now we establish a link between common belief and group belief.

Proposition 1. The equivalence

$$
\mathrm{GBel}_{J} \varphi \leftrightarrow \mathrm{CBel}_{J} \mathrm{GBel}_{J} \varphi
$$

is provable from the axioms of $\mathcal{G} \mathcal{L}$ plus the axioms for common belief.

\footnotetext{
${ }^{9}$ Note that this reduction has no syntactical counterpart: it would require an infinite conjunction. As both Gilbert and Tuomela use common knowledge and common belief operators, Gilbert's simple account is the only reductionist approach where collective beliefs can be syntactically reduced to individual beliefs.
} 
Proof. The proof goes as follows:

1. $\vdash \mathrm{CBel}_{J} \mathrm{GBel}_{J} \varphi \rightarrow \mathrm{GBel}_{i} \mathrm{GBel}_{J} \varphi$,

by $\left(\mathrm{FP}_{\mathrm{CBel}_{J}}\right)$

2. $\vdash \mathrm{CBel}_{J} \mathrm{GBel}_{J} \varphi \rightarrow \mathrm{GBel}_{J} \varphi$

from 1 . by Theorem (4)

3. $\vdash \operatorname{GBel}_{J} \varphi \rightarrow \mathrm{GBel}_{i} \mathrm{GBel}_{J} \varphi$

by Theorem (4), for every $i \in J$

4. $\vdash \mathrm{GBel}_{J} \varphi \rightarrow \bigwedge_{i \in J} \mathrm{GBel}_{i} \mathrm{GBel}_{J} \varphi$

from 3 .

5. $\vdash \operatorname{CBel}_{J}\left(\right.$ GBel $_{J} \varphi \rightarrow \bigwedge_{i \in J}$ GBel $_{i}$ GBel $\left._{J} \varphi\right)$

from 4. by the Rule of Necessitation for $\mathrm{CBel}_{J}$

6. $\vdash \operatorname{CBel}_{J}\left(\mathrm{GBel}_{J} \varphi \rightarrow \bigwedge_{i \in J} \mathrm{GBel}_{i} \mathrm{GBel}_{J} \varphi\right) \rightarrow$

$\left(\bigwedge_{i \in J} \mathrm{GBel}_{i} \mathrm{GBel}_{J} \varphi \rightarrow \mathrm{CBel}_{J} \mathrm{GBel}_{J} \varphi\right)$ from axiom $\mathrm{LFP}_{\mathrm{CBel}_{J}}$

7. $\vdash \bigwedge_{i \in J} \mathrm{GBel}_{i} \mathrm{GBel}_{J} \varphi \rightarrow \mathrm{CBel}_{J} \mathrm{GBel}_{J} \varphi$ from 5. and 6. by Modus Ponens

8. $\vdash \mathrm{GBel}_{J} \varphi \rightarrow \mathrm{CBel}_{J} \mathrm{GBel}_{J} \varphi$

from 4 . and 7.

9. $\vdash \mathrm{GBel}_{J} \varphi \leftrightarrow \mathrm{CBel}_{J} \mathrm{GBel}_{J} \varphi$

from 2 . and 8 .

Proposition 1 tells us that every group belief is commonly believed. Remember that this was one of the requirements for group belief of Sect. 2.3 (we will come back to that in Sect.4.2). This property comes from the public nature of our operator $\mathrm{BBel}_{J}$, cf. the attention property mentioned in Sect. 3.2.

Proposition 2. The equivalence

$$
\left(\neg \mathrm{GBel}_{J} \perp \wedge \mathrm{GBel}_{J} \varphi\right) \leftrightarrow \mathrm{CBel}_{J}\left(\neg \mathrm{GBel}_{J} \perp \wedge \mathrm{GBel}_{J} \varphi\right)
$$

is provable from the axioms of $\mathcal{G} \mathcal{L}$ plus the axioms for common belief.

Proof. By Proposition 1, the schema $\operatorname{GBel}_{J} \varphi \leftrightarrow \mathrm{CBel}_{J} \mathrm{GBel}_{J} \varphi$ is provable. Substituting $\varphi$ by $\neg$ BBel $_{J} \perp \wedge \varphi$ we obtain the theorem

$$
\mathrm{GBel}_{J}\left(\neg \mathrm{GBel}_{J} \perp \wedge \varphi\right) \leftrightarrow \mathrm{CBel}_{J} \mathrm{GBel}_{J}\left(\neg \mathrm{GBel}_{J} \perp \wedge \varphi\right) .
$$

Then the proposition follows from the K45 theorem

$$
\mathrm{GBel}_{J}\left(\neg \mathrm{GBel}_{J} \perp \wedge \varphi\right) \leftrightarrow\left(\neg \mathrm{GBel}_{J} \perp \wedge \mathrm{GBel}_{J} \varphi\right)
$$

together with the rule of replacement of proved equivalents.

We highlight that contrarily to common belief, the negative introspection (axiom 5) holds for group belief. This comes from the fact that the public nature of group belief is stronger than that of common belief. Common belief is public in the sense that if a proposition is commonly believed then this common belief itself is commonly believed. More generally, we can say that a formula $\varphi$ is public for the group $J$ if and only if $\varphi \leftrightarrow \operatorname{CBel}_{J} \varphi$. In this sense, any group belief is public (thanks to Proposition 1). But the publicness of the group belief is stronger because of axiom 5 (i.e., Axiom IN- with $J^{\prime}=J$ ): if a group belief does not hold then the group believes (and thus is aware) that it does not hold. This makes that contrarily to common belief, individual belief cannot be wrong about group beliefs, as already observed in Sect. 4.1.2.

While it should be clear by now that contrarily to common belief, group belief does not logically imply individual belief, it may nevertheless be considered that it does so by default: when we learn that group $J$ believes that $\varphi$ then we often infer 
that $J$ 's members individually believe that $\varphi$. Technically, this could be done by integrating nonmonotonic reasoning mechanisms into $\mathcal{G} \mathcal{L}$.

In Sect. 4.4 we will present a dynamic variant of $\mathcal{G} \mathcal{L}$. Some more differences between group belief and common belief will show up in that setting.

\subsection{Back to the Philosophical Origins}

We now revisit the criteria for group belief that we have put forward in Sect. 2.3 in the light of our logic.

\subsubsection{Group Belief Features}

Group belief has a binding force. As already said, this feature of group belief is made explicit in the reading of our belief operator. We have said that a situation where we have a genuine group belief by $J$ that $\varphi$ should be described by the formula $\mathrm{GBel}_{J} \varphi \wedge \neg \mathrm{GBel}_{J} \perp: J$ is a constituted group in Gilbert's sense, and the $J$ believes $\varphi$.

No combination of individual beliefs implies group belief. In our logic, there is no entailment link between individual beliefs and group beliefs: so in $\mathcal{G} \mathcal{L}$, $\bigwedge_{i \in J} \operatorname{GBel}_{i} \varphi$ neither implies $\neg \mathrm{GBel}_{J} \perp$, nor does it imply $\operatorname{GBel}_{J} \varphi$, so a fortiori $\bigwedge_{i \in J} \operatorname{GBel}_{i} \varphi$ does not imply $\neg \mathrm{GBel}_{J} \perp \wedge \mathrm{GBel}_{J} \varphi$. We can generalize this proof to any combination of individual beliefs, and in particular to common belief.

Group belief does not imply individual belief. Group belief does not imply individual, private belief in our logic: for every agent $i$, be it a member of the group $J$ or not, $\left(\neg \mathrm{GBel}_{J} \perp \wedge \mathrm{GBel}_{J} \varphi\right) \rightarrow \mathrm{GBel}_{i} \varphi$ is not valid in our logic.

There is a commitment on group belief. It is important to note that our logic does not have a separate operator of commitment from which group belief would be defined. Instead, we consider that our notion of group belief incorporates a notion of commitment. This property takes the form:

$$
\left(\neg \mathrm{GBel}_{J} \perp \wedge \mathrm{GBel}_{J} \varphi\right) \rightarrow \mathrm{GBel}_{J} \bigwedge_{i \in J} \mathrm{GBel}_{i} \varphi
$$

This formula is a theorem of our logic due to axiom (AGR) (actually even without the premiss $\neg G B e l_{J} \perp$ ). A belief of group $J$ that $\varphi$ implies the commitment of each group member $i \in J$ to $\varphi$, in the sense that $i$ is declaring (implicitly and towards the group) that he believes $\varphi$. This is 'hard-wired' in the logic: a constituted group belief that $\varphi$ (i.e., $\neg \mathrm{GBel}_{J} \perp \wedge \mathrm{GBel}_{J} \varphi$ ) logically implies group belief that every member believes that $\varphi\left(\mathrm{GBel}_{J} \mathrm{GBel}_{i} \varphi\right.$, for $\left.i \in J\right)$. 
Moreover, if an agent $i$ violates his commitment-e.g. by expressing a contrary point of view - then this destroys the group: the formula $\mathrm{GBel}_{J} \varphi \wedge$ $\mathrm{GBel}_{J} \mathrm{GBel}_{i} \neg \varphi \rightarrow \mathrm{GBel}_{J} \perp$ is provable (thanks to AGR and $\mathrm{D}_{\text {GBel }_{i}}$ ). So the agent is committed to the group beliefs in the sense that, if he wants to stay member of a constituted group Group then he has to act according to beliefs of Group. (This will be made more explicit in our dynamic extension of $\mathcal{G} \mathcal{L}$.)

The group members share a common belief about group beliefs. This is a theorem of our logic: as proved above, the formula $\mathrm{GBel}_{J} \varphi \rightarrow \mathrm{CBel}_{J} \mathrm{GBel}_{J} \varphi$ is provable. Our logic is even stronger because we have an equivalence here.

To sum it up: our logic $\mathcal{G} \mathcal{L}$ satisfies the list of the requirements for a group belief operator that we have postulated in Sect. 2.3. We now examine more deeply its link with Gilbert's and Tuomela's approaches.

\subsubsection{Comparison with Gilbert's Plural Subject Account}

In the sequel, we show that our group belief operator captures Gilbert's group belief definition of Gilbert (1989). This is mainly due to axioms (AGR) and (UNA). In particular, if we consider that $\mathrm{GBel}_{J} \mathrm{GBel}_{i} \varphi$ typically results from agent $i$ expressing in front of group $J$ that he believes $\varphi$ (and this fact being collectively accepted as a group belief) then Axiom (UNA): $\operatorname{GBel}_{J}\left(\left(\bigwedge_{i \in J} \mathrm{GBel}_{i} \varphi\right) \rightarrow \varphi\right)$ says that a group belief results from the expression of an individual belief by all members of the group. By making public their belief that $\varphi$ holds, the agents in $J$ publicly express their opinions that $\varphi$ should be accepted by the group $J$.

Moreover, from the theorem (3) of Sect.3.3, Proposition 1 and the rule of substitution of proved equivalents we can deduce the equivalence:

$$
\operatorname{GBel}_{J} \varphi \leftrightarrow \mathrm{CBel}_{J}\left(\bigwedge_{i \in J} \mathrm{GBel}_{J} \mathrm{GBel}_{i} \varphi\right)
$$

According to the above remark this formula may be read: " $\varphi$ is a group belief of $J$ if and only if it is common belief in $J$ that every group member publicly expressed that he believes $\varphi$ ". This equivalence is thus very close to Gilbert's characterization of group belief. ${ }^{10}$

\subsubsection{Comparison with Tuomela's Account}

Our simple logical framework does not allow to capture the whole complexity of Tuomela's refinement of Gilbert definition of group belief that we have mentioned in the end of Sect.2.2.1. In particular, in $\mathcal{G} \mathcal{L}$ we do not have roles, institution or

\footnotetext{
${ }^{10}$ It may be argued that we do not entirely capture Gilbert's intended sense of commitment in our logic: a fully-fledged account should have a primitive modal operator of commitment. In any case, we believe that $\mathcal{G L}$ is the best that can be done with a logic that has only modal operators of belief.
} 
norms, and we cannot distinguish between operative and non-operative agents. We however note that our logic can be easily extended by introducing the concept of 'leaders of a group $J$ about a proposition $\varphi$ ', noted leaders $(J, \varphi)$. The leaders would be a subgroup of the group of agents $J$, verifying properties such as: $\operatorname{GBel}_{J}\left(\operatorname{GBel}_{\text {leaders }(J, \varphi)} \varphi \leftrightarrow \varphi\right)$. This means that it is grounded for the whole group $J$ that if it is grounded for its leaders that $\varphi$, then $\varphi$ true (i.e., if leaders have jointly accepted $\varphi$, then the other agents have to accept it tacitly and thus $\varphi$ becomes a proper group belief $a ̀$ la Tuomela). The group of leaders could be for example the government for every decision concerning the whole nation or a group of specialists of a domain for every fact concerning their domain of competence.

\subsection{The Relationships Between the Logic of Group Belief and the Logic of Acceptance}

The logic $\mathcal{A L}$ (Acceptance Logic) that was introduced in Gaudou et al. (2008), Lorini et al. (2009), and Herzig et al. (2009) has some similarities with our logic of group belief $\mathcal{G} \mathcal{L}$. $\mathcal{A} \mathcal{L}$ allows to express what agents accept while functioning as members of a certain institution $x$; in particular, $\mathcal{A L}$ allows to express that some agents identify themselves as members of $x$.

The logic $\mathcal{A L}$ has been exploited in order to model the relationship between acceptances and institutions and, in particular, in order to clarify how the existence and the dynamics of norms and rules of an institution might depend on their acceptance by the members of the institution. In the logic of acceptance, institutions are conceived as rule-governed social practices on the background of which the agents reason. For example, take the case of a game like Clue. The institutional context is the rule-governed social practice which the agents conform to in order to be competent players and on the background of which agents reason. In the context of Clue, an agent accepts that something has happened qua player of Clue (e.g., the agent accepts that Mrs. Red is the murderer qua player of Clue). The logic $\mathcal{A L}$ is aimed at capturing the state of acceptance qua member of an institution as the kind of acceptance one is committed to when one is "functioning as a member of the institution". It is proved in Lorini et al. (2009) that the logic of acceptance $\mathcal{A L}$ embeds the logic of normative systems of Grossi et al. (2006).

$\mathcal{A L}$ has operators for acceptance of the form $A_{J: x}$, which are interpreted by means of accessibility relations $\mathscr{A}_{J: x}$ between states in a model. The formula $A_{J: x} \varphi$ is read 'the agents in $J$ accept that $\varphi$ while functioning as members of institution $x$ '. The formula $A_{J: x} \perp$ has therefore to be read 'agents in $J$ are not functioning as members of institution $x$ '; conversely, $\neg A_{J: x} \perp$ has to be read 'agents in $J$ are functioning as members of institution $x$ '. Thus, $\neg A_{J: x} \perp \wedge A_{J: x} \varphi$ means 'agents in $J$ accept that $\varphi$ qua members of institution $x$ '. For singletons the formula $\neg A_{i: x} \perp \wedge A_{i: x} \varphi$ has to be read 'agent $i$ accepts that $\varphi$ qua member of institution $x$ '. 
The axiomatization of $\mathcal{A L}$ is as follows, where $x$ and $y$ denote institutional contexts.

All K-principles for the operators $A_{J: x}$

$$
\begin{array}{cr}
A_{J: x} \varphi \rightarrow A_{J^{\prime}: y} A_{J: x} \varphi \text { for } J^{\prime} \subseteq J & \left(\mathrm{IN}+_{A_{J}: x}\right) \\
\neg A_{J: x} \varphi \rightarrow A_{J^{\prime}: y} \neg A_{J: x} \varphi \text { for } J^{\prime} \subseteq J & \left(\mathrm{IN}-A_{J: x}\right) \\
A_{J: x}\left(\left(\bigwedge_{i \in J} A_{i: x} \varphi\right) \rightarrow \varphi\right) & \left(\mathrm{UNA}_{A_{J}: x}\right) \\
\left(\neg A_{J: x} \perp \wedge A_{J: x} \varphi\right) \rightarrow A_{J^{\prime}: x} \varphi \text { for } J^{\prime} \subseteq J & \\
\neg A_{J: x} \perp \rightarrow \neg A_{J^{\prime}: x} \perp \text { for } J^{\prime} \subseteq J & (\mathrm{INCL})
\end{array}
$$

Axioms $\mathrm{IN}+_{A_{J}: x}$ and $\mathrm{IN}-A_{J: x}$ are introspection axioms for acceptance which are similar to the Axioms IN+ and IN- for group belief. Axiom $\mathrm{UNA}_{A_{J}: x}$ is a unanimity principle which describes the bottom up process leading from individual acceptances of the members of an institution to the collective acceptance of the group of members of the institution. This axiom is similar to Axiom UNA of the logic of group belief.

The Inclusion Axiom INCL says that, if the agents in $J$ accept that $\varphi$ qua members of $x$ then every subset $J^{\prime}$ of $J$ accepts $\varphi$ while functioning as members of $x$. This means that things accepted by the agents in $J$ qua members of $x$ are necessarily accepted by the agents in all of $J$ 's subsets with respect to the same institutional context $x$. The axiom describes the top down process leading from $J$ 's collective acceptance to the individual acceptances of $J$ 's members.

We observe that there is no such principle in $\mathcal{G} \mathcal{L}$. In fact, an axiom such as $\left(\neg \mathrm{GBel}_{J} \perp \wedge \mathrm{GBel}_{J} \varphi\right) \rightarrow \mathrm{GBel}_{J^{\prime}} \varphi$ with $J^{\prime} \subseteq J$ would be too strong: as we have argued, a group's beliefs may differ from the beliefs of its supergroups. On the contrary, Axiom INCL sounds reasonable for the logic of acceptance which mentions explicitly the (institutional, conversational or social) context in which the acceptance of a group of agents is taking place.

Another difference with $\mathcal{G L}$ is that in $\mathcal{A L}$, groups of an institution are supposed to be closed under subsets (Axiom CS). In fact, the formula $\neg A_{J: x} \perp$ is not aimed at capturing a strong notion of 'constituted group'. As said above, the $\mathcal{A L}$ formula $\neg A_{J: x} \perp$ has to be read 'agents in $J$ are functioning as members of $x$ '. The latter expression just means that: every agent in $J$ identifies himself as a member of $x$ and recognizes every agent in $J$ as a member of $x$. Under this assumption, $\neg A_{J: x} \perp$ should imply $\neg A_{J^{\prime}: x} \perp$, for $J^{\prime} \subseteq J$. As argued in Sect. 3.4, Axiom CS would be unreasonable for $\mathcal{G L}$, where the formula $\neg G B e l_{J} \perp$ is aimed at capturing a notion of constituted group.

Although $\mathcal{G} \mathcal{L}$ and $\mathcal{A L}$ have some different principles and properties, under certain conditions it is possible to find a translation from $\mathcal{G L}$ to $\mathcal{A L}$ such that axioms and rules of inference of $\mathcal{G} \mathcal{L}$ are theorems of $\mathcal{A L}$. To this end, a single institutional context $x_{0}$ is enough. Consider the following translation $\operatorname{tr}$ from $\mathcal{G L}$ to $\mathcal{A L} \mathcal{L}^{+}$: 
- $\operatorname{tr}(p)=p$,

- $\operatorname{tr}(\neg \varphi)=\neg \operatorname{tr}(\varphi)$,

- $\operatorname{tr}(\varphi \vee \psi)=\operatorname{tr}(\varphi) \vee \operatorname{tr}(\psi)$,

- $\operatorname{tr}\left(\operatorname{GBel}_{J} \varphi\right)=A_{J: x_{0}} \operatorname{tr}(\varphi)$.

Proposition 3. For every $\mathcal{G} \mathcal{L}$ formula $\varphi$, if $\varphi$ is a theorem of $\mathcal{G} \mathcal{L}$ then

$$
\bigwedge_{i \in A G T} \neg A_{i: x_{0}} \perp \models \operatorname{tr}(\varphi)
$$

is a theorem of $\mathcal{A L}^{+}$(where $\models$ is logical consequence with global axioms as defined in Sect. 3.2).

Although Proposition 3 highlights some interesting relationships between $\mathcal{A} \mathcal{L}$ and $\mathcal{G L}$, we cannot prove that the former embeds the latter, i.e. it seems difficult to find a straightforward translation $\operatorname{tr}$ from $\mathcal{G L}$ to $\mathcal{A L}$ such that $\varphi$ is $\mathcal{G L}$ satisfiable iff $\operatorname{tr}(\varphi)$ is $\mathcal{A L}$ satisfiable. In fact, the two logics aim to capture different kinds of individual and collective attitudes. In Gaudou et al. (2008) and Lorini et al. (2009) the authors were interested in clarifying what 'accepting something qua member of an institution' means, and in studying the relationships between acceptances and institutions. In the present work, we have provided a logical formalization of group belief trying to account for the main properties of this concept which have been identified in the philosophical literature on collective Intentionality. Both works are however part of the same general program which consists in the logical analysis of different kinds of collective and group attitudes and of their relationships with individual attitudes (beliefs, preferences, etc.) and with social structures like institutions and organizations.

\subsection{A Dynamic Variant of the Logic of Group Belief}

In this section we discuss a dynamic variant of our logic where group beliefs are updated by public announcements. Our logic extends $\mathcal{G} \mathcal{L}$ just as public announcement logic (PAL) extends epistemic logic (van Ditmarsch et al. 2007). We extend $\mathcal{G} \mathcal{L}$ by modal operators of public announcement of the form $[\varphi !]$. $[\varphi$ !] $\psi$ reads "if $\varphi$ is publicly announced then $\psi$ is true afterwards".

We adopt Kooi's semantics (which is a variant of the original PAL (Kooi 2007)) because it better suits belief (while the original PAL better suits knowledge). The truth condition for the operators of public announcement is:

$$
M, w \models[\varphi !] \psi \text { iff } M^{\varphi !}, w \models \psi
$$

The components of the update $M^{\varphi !}$ of $M$ by $\varphi$ ! are defined as follows:

- $W^{\varphi !}=W$;

- $u^{\varphi} \mathscr{G}_{J}^{\varphi !} v$ iff $w^{\mathscr{G}_{J}} v$ and $M, v \models \varphi$, for every $J \subseteq A G T$;

- $\mathscr{V}^{\varphi !}(p)=\mathscr{V}(p)$, for every $p \in$ ATM. 
The effect of a public announcement $\varphi$ ! is to restrict the set of worlds that are compatible with what is believed by the group $J$ to the set of worlds in which $\varphi$ is true, for every group $J$. Note that it might be the case that before the announcement of $\varphi$, an agent $i$ believes that $\neg \varphi$ : then the announcement empties $i$ 's set of possible worlds. This is the reason why the semantic constraint 5 given in Sect. 3.2 must be abandoned in this dynamic extension of the logic of group belief. For the rest, it is straightforward to verify that if $M$ satisfies the semantic constraints $1-4$ of in Sect. 3.2 then $M^{\varphi !}$ does so, too.

Call $\mathcal{G} \mathcal{L}^{-}$the variant of $\mathcal{G} \mathcal{L}$ without constraint 5 , and call PA- $\mathcal{G} \mathcal{L}^{-}$the extension of $\mathcal{G} \mathcal{L}^{-}$by public announcements. It is a routine task to prove that the following equivalences are valid in $\mathrm{PA}-\mathcal{G} \mathcal{L}^{-}$:

$$
\begin{array}{cr}
{[\varphi !] p \leftrightarrow p} & \left(\operatorname{Red}_{p}\right) \\
{[\varphi !] \neg \varphi \leftrightarrow \neg[\varphi !] \varphi} & \left(\operatorname{Red}_{\neg}\right) \\
{[\varphi !](\psi \wedge \chi) \leftrightarrow([\varphi !] \psi \wedge[\varphi !] \chi)} & \left(\operatorname{Red}_{\wedge}\right) \\
{[\varphi !] G \operatorname{Bel}_{J} \psi \leftrightarrow \operatorname{GBel}_{J}(\varphi \rightarrow[\varphi !] \psi)} & \left(\operatorname{Red}_{G B e l_{J}}\right)
\end{array}
$$

They make up a complete set of reduction axioms: together with the rule of replacement of proved equivalences they allow to 'push' the dynamic operators $[\varphi$ !] through the logical operators of $\mathcal{G} \mathcal{L}$, and in this way to reduce every formula containing dynamic operators to a provably equivalent formula without dynamic operators. So, completeness of PA-G $\mathcal{L}^{-}$follows from the known completeness of the base logic without dynamic operators that we have established in Sect. 3.3 (more precisely, of the variant $\mathcal{G L}^{-}$without the $\mathrm{D}$-axiom, which can be proved straightforwardly).

The reduction axiom $\left(\operatorname{Red}_{\text {GBel }_{J}}\right)$ for group belief highlights an important difference between our logic and the logic of common belief: there is no such reduction axiom for common belief and common knowledge (Kooi and van Benthem 2004). Technically, this difference can be explained by the way group belief and common belief relate to individual beliefs. On the one hand, common belief is strongly linked to individual beliefs and can be semantically reduced to them: common belief of a set of agents $J$ is interpreted by means of the transitive closure of the union of the accessibility relations associated to the individuals in $J$. In contrast, the accessibility relation for group belief of $J$ cannot be defined from those for individual beliefs. In other words, a group belief of $J$ entertains a much weaker link with the individual beliefs of the agents in $J$ than common belief does. The difference is perhaps easier to understand with an example.

Let $M$ be a model with three worlds $W=\{w, v, u\}$ such that $\mathscr{V}(p)=$ $\{w, v\}$ and $\mathscr{V}(q)=\{w, u\}$. Suppose also that $\mathscr{G}_{i}=\{(w, v),(v, v),(u, u)\}, \mathscr{G}_{j}=$ $\{(w, w),(v, u),(u, u)\}$ and $\mathscr{G}_{\{i, j\}}=\{(w, u),(v, u),(u, u)\}$. By definition of $\mathscr{C}_{\{i, j\}}$, we have $\mathscr{C}_{\{i, j\}}=\{(w, w),(w, v),(w, u),(v, u),(v, v),(u, u)\}$. Note that even though $M, w \not \models \operatorname{CBel}_{\{i, j\}}(q \rightarrow[q !] p)$, we still have $M, w \models[q !] \operatorname{CBel}_{\{i, j\}} p$. Indeed, in the model $M^{q !}$ resulting from the announcement of $q$ we have $\mathscr{C}_{\{i, j\}}^{q !}(w)=\{w\}$. In words, it is not common belief that $q$ implies that $p$ is the case after the public announcement 
of $q$, but after the public announcement of $q$ it is common belief that $p$. That is, common belief may appear 'out of the blue': it was not foreseeable by the agents and just 'pops up'. Consider now group belief. We have $M, w \not \models \operatorname{GBel}_{\{i, j\}}(q \rightarrow[q !] p)$, and also $M, w \not \models[q !] G B e l_{\{i, j\}} p$. Indeed, in the model $M^{q !}$ resulting from the announcement of $q$ to $J$ we have $\mathscr{G}_{\{i, j\}}^{q !}(w)=\{w, u\}$. That is, contrary to common belief, group belief cannot just pop up if not previously foreseen by the agents.

Let us consider a further aspect of this dynamic extension of the logic of group belief. In Sect. 4.2.1 we have shown that if a (constituted) group $J$ believes that $\varphi$ (i.e., $\neg \mathrm{GBel}_{J} \perp \wedge \mathrm{GBel}_{J} \varphi$ ) then every member of the group is committed to the fact that $\varphi$ is true in front of the other members of the group (i.e., $\mathrm{GBel}_{J} \bigwedge_{i \in J} \mathrm{GBel}_{i} \varphi$ ): the group $J$ believes that each of its members might declare that he believes $\varphi$. Operations of public announcement can be used in order to model commitment dynamics and group belief dynamics by means of (very simple kind of) speech acts. The following valid formulas highlight this.

First,

$$
\left[\mathrm{GBel}_{i} p !\right] G B e l_{J} \mathrm{GBel}_{i} p
$$

says that when $i$ asserts that $p$ is true publicly then $i$ becomes committed to the fact that $p$ is true towards $J$ (where $J$ might include $i$ ). We suppose indeed that the announcement $G B e l_{i} p$ ! captures a basic notion of assertion, that is, $G_{B e l} p$ ! corresponds to the event "agent $i$ asserts that $p$ is true publicly".

Second,

$$
\left[\left(\bigwedge_{i \in J} \operatorname{GBel}_{i} \varphi\right) !\right] G B e l_{J} p
$$

says that after every agent in $J$ has asserted that $p, J$ starts to believe that $p$. Here is a sequential version, for $J=\left\{i_{1}, \ldots, i_{n}\right\}$ :

$$
\left[\operatorname{GBel}_{i_{1}} \varphi !\right] \ldots\left[\mathrm{GBel}_{i_{n}} \varphi !\right] G \mathrm{Gel}_{J} p
$$

Let us prove theorem (9). First, observe that [ $\left.\bigwedge_{i \in J} G B_{e l} p !\right] G B e l_{J} p$ is equivalent to

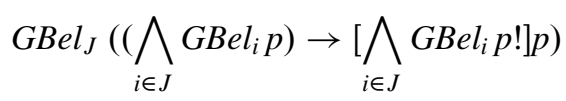

(by the reduction axiom $\left.\left(\operatorname{Red}_{G B e l_{J}}\right)\right)$. The latter is equivalent to $\operatorname{GBel}_{J}\left(\left(\bigwedge_{i \in J} G \operatorname{Cel}_{i} p\right) \rightarrow p\right)$ (by reduction axiom $\left.\left(\operatorname{Red}_{p}\right)\right)$, which is nothing but the Unanimity Axiom UNA. Therefore $\left[\bigwedge_{i \in J} G_{B e l} p !\right] G B e l_{J} p$ must be a theorem of PA- $\mathcal{G} \mathcal{L}^{-}$.

Before concluding, we note that our definition of assertion forces agents to trust the sincerity of other agents. Indeed, as a specific instance of formula (8) above, we have

$$
\left[\mathrm{GBel}_{i} p !\right] G B \mathrm{Gl}_{j} \mathrm{GBel}_{i} p
$$


That is, when agent $i$ asserts $p$ then every agent $j$ believes that $i$ believes $p$. This is of course a limitation of this dynamic extension of $\mathcal{G} \mathcal{L}$, one that that we intend to overcome in future works. To this aim, we plan to use an approach based on action/event models à la (Baltag et al. 1998). This amounts to defining an update operation which changes group beliefs without directly changing the agents' individual beliefs. Such an operation allows for situations where an agent $i$ asserts that $p$ towards a group $J$ and $J$ starts to believe that $i$ believes $p$ while no agent $j$ in $J$ individually believes that $i$ believes $p$ (as there is no agent $j$ trusting $i$ ). However, one has to be careful here: it is not straightforward to define an update operation in such a way that the updated model still satisfies the semantic constraints $1-5$. For a solution in the case of acceptance see Herzig et al. (2009).

\section{Conclusion}

We have focussed on the characterization and the formalization of the notion of group belief, in the sense of a belief ascribed to a group as a whole. In the first part of the paper we have presented an overview of existing philosophical theories of collective belief (by presenting Gilbert's and Tuomela's accounts), and we have shown that a notion of group belief should not be confused with a reductionist view of collective belief as an aggregate of individual beliefs of some agents. Following this overview, we have highlighted the key features of group belief and have modeled them semantically and axiomatically in our logic $\mathcal{G} \mathcal{L}$. We have then discussed the formal links between the notion of group belief (i.e., our group belief operator) and a reductionist notion of collective belief embodied by the common belief operator. In addition, we have presented a comparison between the logic of group belief and the logic of collective acceptance. Finally, we have discussed a dynamic variant of our logic, which is the first step to cover group belief formation.

The dynamic extension of Sect. 4.4 is only the first step to cover group belief formation as it occurs e.g. in Example 12. A more sophisticated account would require the integration of a theory of communication (typically, speech act theory (Searle 1969)) and of mechanisms of group belief formation beyond unanimity, as studied in social choice theory (Taylor 2005).

In the future we also plan to extend our formal analysis of collective attitudes to group intentions. To this end, we will have to supplement the logical framework presented in this paper with operators for individual goals (or individual preferences) of the form $\operatorname{Pref}_{i}$ where $i$ refers to an individual agent and the formula $\operatorname{Pref}_{i} \varphi$ means 'agent $i$ prefers $\varphi$ ' (or 'agent $i$ wants $\varphi$ to be true'). Again, following Gilbert, we can say that the agents in a group $J$ have the intention to do the joint action $\delta_{J}$ together (or the agents in $J$ are jointly ready to do the joint action $\delta_{J}$ together) if and only if the agents in $J$ have openly expressed their willingness to do $\delta_{J}$ together. We think that a preliminary formalization of this concept of group intention is expressed by the formula $\operatorname{GBel}_{J}\left(\bigwedge_{i \in J} \operatorname{Pref}_{i} \delta_{J}\right)$. We postpone to future work an in-depth analysis of this concept of group intention, of the formal relationships 
between the operator of group belief $\mathrm{GBel}_{J}$, the operators of individual preference $\operatorname{Pref}_{i}$, and the constructions for joint action of type $\delta_{J}$.

\section{References}

Ågotnes, Thomas. 2012. What noone knows. In 10th conference on logic and the foundations of game and decision theory (LOFT 2012), Sevilla.

Aumann, Robert. 1976. Agreeing to disagree. Annals of Statistics 4: 1236-39.

Baltag, Alexandru, Larry Moss, and Slawomir Solecki. 1998. The logic of public announcements, common knowledge and private suspicions. In Proceedings of the seventh conference on theoretical aspects of rationality and knowledge (TARK'98), ed. Itzhak Gilboa, 43-56. San Francisco: Morgan Kaufmann.

Bonanno, Giacomo, and Klaus Nehring. 2000. Common belief with the logic of individual belief. Mathematical Logic Quarterly 46(1): 49-52.

Bratman, Michael E. 1987. Intention, plans, and practical reason. Cambridge: Harvard University Press.

Brentano, Franz. 1995. Psychology from an empirical standpoint. London: Routledge.

Chellas, Brian F. 1980. Modal logic: An introduction. Cambridge/New York: Cambridge University Press.

Cohen, L. Jonathan. 1989. Belief and acceptance. Mind 391(XCVIII): 367-389.

Cohen, Philip R., and Hector J. Levesque. 1990. Intention is choice with commitment. Artificial Intelligence Journal 42(2-3): 213-261

Dennett, Daniel. 1987. The intentional stance. Cambridge: MIT.

Durkheim, Emile. 1982. The rules of sociological method. New York: Free.

Durkheim, Emile, and Marcel Mauss. 1963. Primitive classification. Chicago: University of Chicago Press.

Fagin, Ronald, Joseph Y. Halpern, Yoram Moses, and Moshe Y. Vardi. 1995. Reasoning about knowledge. Cambridge/London: MIT.

Gaudou, Benoit, Dominique Longin, Emiliano Lorini, and Luca Tummolini. 2008. Anchoring institutions in agents' attitudes: Towards a logical framework for autonomous multi-agent systems. In International joint conference on autonomous agents and multiagent systems (AAMAS), Estoril, 728-735. ACM.

Gilbert, Margaret. 1987. Modelling collective belief. Synthese 73(1): 185-204.

Gilbert, Margaret. 1989. On social facts. London/New York: Routledge.

Gilbert, Margaret. 1996. Living together: Rationality, sociality, and obligation. Lanham: Rowman and Littlefield.

Gilbert, Margaret. 2002. Belief and acceptance as features of groups. Protosociology 16: 35-69.

Grossi, Davide, John-Jules Ch. Meyer, and Frank Dignum. 2006. Classificatory aspects of countsas: An analysis in modal logic. Journal of Logic and Computation 16(5): 613-643.

Hakli, Raul. 2006. Group beliefs and the distinction between belief and acceptance. Cognitive Systems Research 7: 286-297.

Heal, Jane. 1978. Common knowledge. Philosophical Quarterly 28: 116-131.

Herzig, Andreas, Tiago de Lima, and Emiliano Lorini. 2009. On the dynamics of institutional agreements. Synthese - Knowledge representation for agents and multi-agent systems 171(2): 321-355.

Herzig, Andreas, Emiliano Lorini, Jomi F. Hübner, and Laurent Vercouter. 2010. A logic of trust and reputation. Logic Journal of the IGPL 18(1): 214-244. Special Issue "Normative Multiagent Systems".

Hintikka, Jaakko. 1962. Knowledge and belief: An introduction to the logic of the two notions. Ithaca: Cornell University Press. 
Kooi, Barteld. 2007. Expressivity and completeness for public update logic via reduction axioms. Journal of Applied Non-Classical Logics 17(2): 231-253.

Kooi, B., and J. van Benthem. 2004. Reduction axioms for epistemic actions, In AiML-2004: Advances in Modal Logic, ed. R. Schmidt, I. Pratt-Hartmann, M. Reynolds, H. Wansing, number UMCS-04-9-1 in Technical Report Series, University of Manchester, pp. 197-211.

Lewis, David. 1969. Convention. Cambridge: Harvard University Press.

Lewis, David. 1972. Language and language. Minnesota Studies for the Philosophy of Science VII: 3-35.

Lorini, Emiliano, Dominique Longin, Benoit Gaudou, and Andreas Herzig. 2009. The logic of acceptance: Grounding institutions on agents' attitudes. Journal of Logic and Computation 19(6): 901-940.

Meijers, Anthonie. 1999. Believing and accepting as a group. In Belief, cognition and the will, 59-71. Tilburg: Tilburg University Press.

Meijers, Anthonie. 2002. Collective agents and cognitive attitudes. Protosociology 16: 20-85.

Meijers, Anthonie. 2003. Why accept collective beliefs? Reply to Gilbert. Protosociology 18-19: 377-388

Quinton, Anthony. 1976. Social objects. Proceedings of the Aristotelian Society LXXVI: 1-27.

Sahlqvist, Henrik. 1975. Completeness and correspondence in the first and second order semantics for modal logics. In Proceedings of the 3rd Scandinavian Logic Symposium (Univ. Uppsala, Uppsala, 1973), Studies in logic and the Foundations of Mathematics, vol. 82, ed. S. Kanger. Amsterdam: North-Holland

Schiffer, Stephen. 1972. Meaning. Oxford: Oxford University Press.

Searle, John R. 1969. Speech acts: An essay in the philosophy of language. New York: Cambridge University Press.

Searle, John R. 1983. Intentionality: An essay in the philosophy of mind. New York: Cambridge University Press.

Searle, John R. 1995. The construction of social reality. New York: Free Press.

Taylor, A.D. 2005. Social choice and the mathematic of manipulation. Cambridge/New York: Cambridge University Press.

Tollefsen, Deborah Perron. 2002. Challenging epistemic individualism. Protosociology 16: 86-117.

Tuomela, Raimo. 1992. Group beliefs. Synthese 91(3): 285-318.

Tuomela, Raimo. 2000. Belief versus acceptance. Philosophical Explorations 2: 122-137

van Ditmarsch, Hans, Wiebe van der Hoek, and Barteld Kooi. 2007. Dynamic epistemic logic. Synthese Library, vol. 337. Dordrech: Springer.

Wray, K. Brad. 2001. Collective belief and acceptance. Synthese 3(129): 319-333.

Wray, K. Brad. 2003. What really divides Gilbert and the rejectionnists. Protosociology 18-19: 363-376 